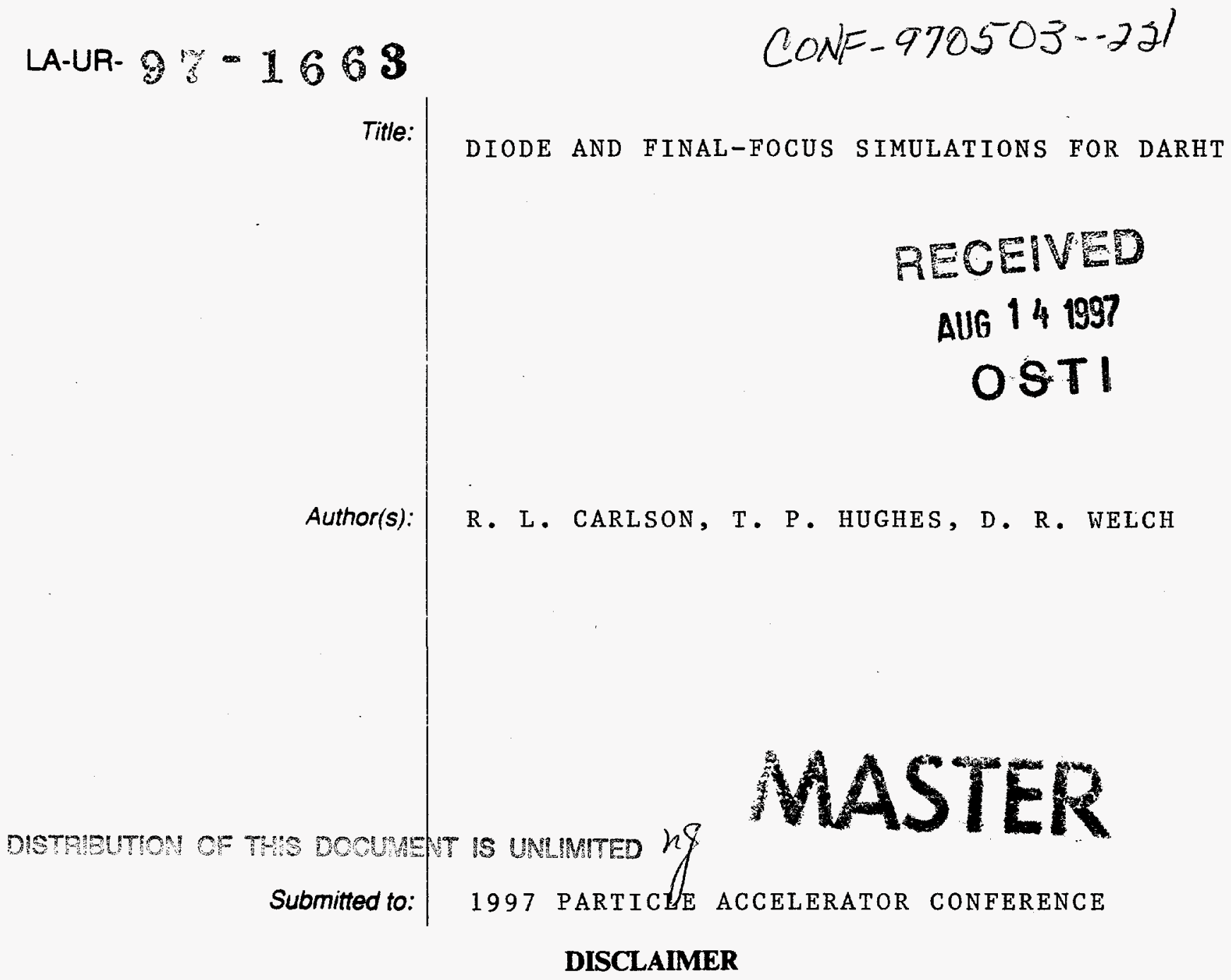

This report was prepared as an account of work sponsored by an agency of the United States Government. Neither the United States Government nor any agency thereof, nor any of their employees, makes any warranty, express or implied, or assumes any legal liability or responsibility for the accuracy, completeness, or usefulness of any information, apparatus, product, or process disclosed, or represents that its use would not infringe privately owned rights. Reference herein to any specific commercial product, process, or service by trade name, trademark, manufacturer, or otherwise does not necessarily constitute or imply its endorsement, recommendation, or favoring by the United States Government or any agency thereof. The views and opinions of authors expressed herein do not necessarily state or reflect those of the United States Government or any agency thereof.

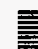
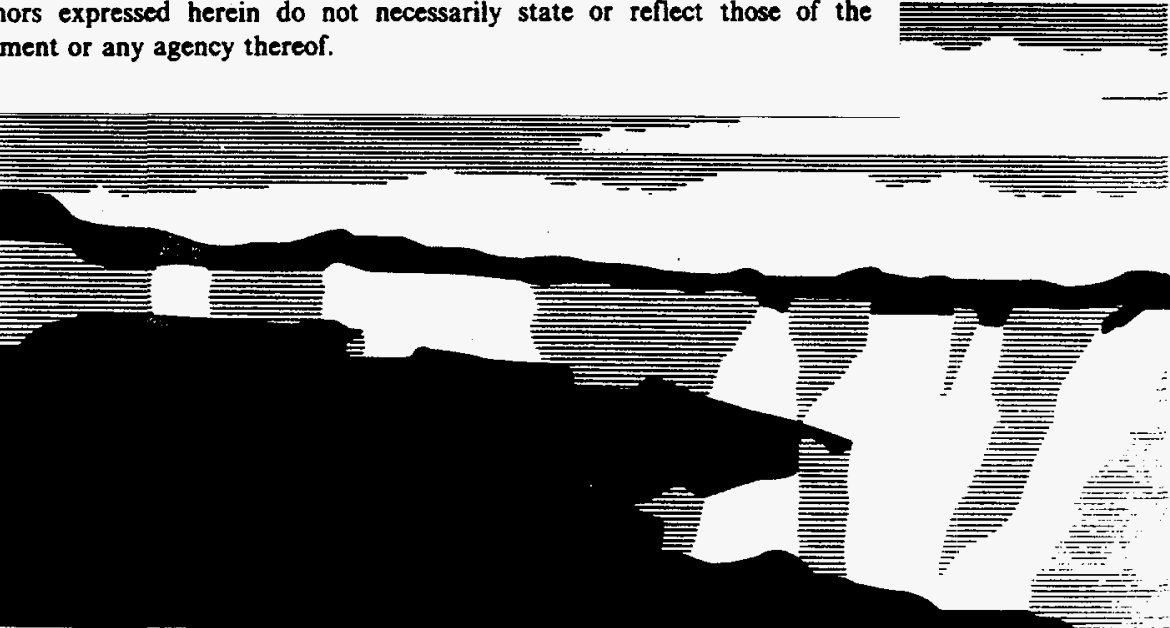

Los Alamos National Laboratory, an affirmative action/equal opportunity employer, is operated by the University of Califomia for the U.S. Department of Energy under contract W-7405-ENG-36. By acceptance of this article, the publisher recognizes that the U.S. Govemment retains a nonexchusive, royalty-tree license to publish or reproduce the publiahed form of this contribution, or to allow others to do so, for U.S. Govemment purposes. The Los Alamos National Laboratory requests that the publiaher identify this article as work performed under the auspices of the U.S. Department of Energy. 


\section{DISCLAMIER}

Portions of this document may be illegible in electronic image products. Images are produced from the bet available original document. 


\title{
Diode and Final-Focus Simulations for DARHT
}

\author{
Thomas P. Hughes and Dale R. Welch \\ Mission Research Corporation, Albuquerque, NM 87106 \\ Randolph L. Carlson \\ Los Alamos National Laboratory, Los Alamos, NM 87545
}

\section{Abstract}

Beam dynamics calculations for the injector and final-focus region of a $4 \mathrm{kA}, 20 \mathrm{MeV}$ linear induction accelerator are presented. The injector is a low-emittance $4 \mathrm{MeV}$ thermionic or photocathode diode designed to produce four $70 \mathrm{~ns}$ pulses over $2 \mu \mathrm{sec}$. Due to the long total pulse length, we have kept the field stress to $<200 \mathrm{kV} / \mathrm{cm}$ over the cathode electrode, and to $\approx 50 \mathrm{kV} / \mathrm{cm}$ on the radial insulator stacks. The normalized edge emittance produced by the diode is only $\approx 0.019 \mathrm{~cm}$-rad. In the final-focus region, we have modelled the effect of ion emission from the target. The intense electric field of the beam at the 1-mm-diameter focal spot produces substantial ion velocities, and, if the space-charge-limited current density can be supplied, significant focal spot degradation may occur due to ion spacecharge. Calculations for the existing Integrated Test Stand, which has a larger focal spot, show that the effect should be observable for $\mathrm{H}^{+}$and $\mathrm{C}^{+}$ion species. The effect is lessened if there is insufficient ion density on the target to supply the space-charge-limited current density, or if the ion charge-to-mass ratio is sufficiently small.

\section{INTRODUCTION}

The Dual-Axis Radiographic Hydrodynamics Test Facility (DARHT) will use tightly-focused electron beams to create large X-ray doses with a time-integrated spot-size on the order of $1 \mathrm{~mm}[1,2]$. The first axis of DARHT, currently under construction at Los Alamos National Laboratory, is a nominally $20 \mathrm{MeV}, 4 \mathrm{kA}$ linear induction accelerator providing a single pulse with a 60 ns flat-top. One proposal for the second axis of the facility is to generate up to four pulses over a period of $2 \mu \mathrm{sec}$ [3]. We have designed a lowemittance thermionic injector, described in Sec. 2 , for the second axis. The diode provides $4 \mathrm{kA}$ at $4 \mathrm{MeV}$. The beam has been transported through the first 8 induction accelerating gaps, demonstrating that the low emittance is preserved over that distance.

At the other end of the accelerator, the beam is focused onto an X-ray converter to produce a spot with a diameter of about $1 \mathrm{~mm}$. Numerical simulations presented in Sec. 3 show that if the target becomes a space-charge-limited source of light ions, then significant disruption of the focal spot is possible as the ions move upstream. We have calculated the effect for an existing $3.85 \mathrm{kA}, 5.5 \mathrm{MeV}$ prototype for DARHT, the Integrated Test Stand (ITS) [1, 2], and find that the effect should be observable.

\section{LOW-EMITTANCE 4 KA INJECTOR}

The injector we have designed to produce four discrete pulses for DARHT is based on the present ITS injector $[4,5]$. The latter is a $4 \mathrm{MeV}, 4 \mathrm{kA}$ diode with a flat velvet cathode set in a flat electrode. The pulse has excellent voltage and current flatness, and reproducibility. The beam emittance is dominated by the thermal emittance introduced at the emission surface, and has been measured to be $\approx 0.16 \mathrm{~cm}$-rad (normalized Lapostolle edge emittance). For the 4-pulse injector, we have modified the design in order to reduce electrode field stresses (since the stresses are applied for a longer time), and also to take advantage of a low-emittance thermionic- or photo-cathode. The injector layout is shown in Fig. 1. Metglas cores, 10 on one side and

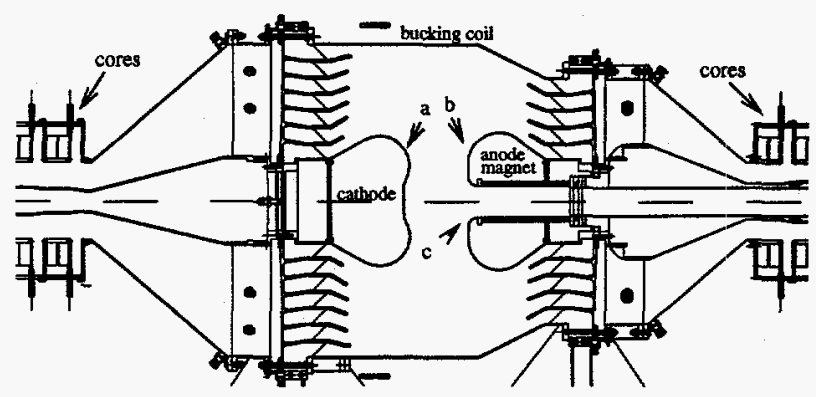

Figure 1: Layout of 4-pulse injector. The field stresses $(\mathrm{kV} / \mathrm{cm}$ ) with (without) the beam at the points marked are: (a) 184 (187), (b) 161 (157) (c) 185 (159).

6 on the other, each provide about $0.25 \mathrm{MeV}$ of inductive voltage, summing to $4 \mathrm{MeV}$ across the AK gap. A Piercelike electrode surrounding the emission area replaces the flat electrode on the ITS injector because (a) it keeps the current density at the cathode surface below $20 \mathrm{~A} / \mathrm{cm}^{2}$ (a reasonable number for a thermionic emitter) and (b) edge effects which contribute to the beam emittance in the ITS are reduced. The AK gap, defined as the distance from the emission surface to the nearest plane intersecting the anode, is $33.7 \mathrm{~cm}$. The emission-surface radius is $8.9 \mathrm{~cm}$ and the radius-of-curvature of the cathode shroud is $16.25 \mathrm{~cm}$.

Using the PBGUNS [6] code, we calculated the field stresses along the cathode and anode electrodes. The maximum values are given in Fig. 1. These values are lower than those for the ITS injector by factors of $0.6-0.7$ and are in line with commonly used scaling laws for breakdown as a function of pulse length.

To model the detailed optics of the diode, we used the particle-in-cell code IVORY. Results are shown in Fig. 2. The simulation is carried out with a mesh size $(\Delta z, \Delta r)$ 

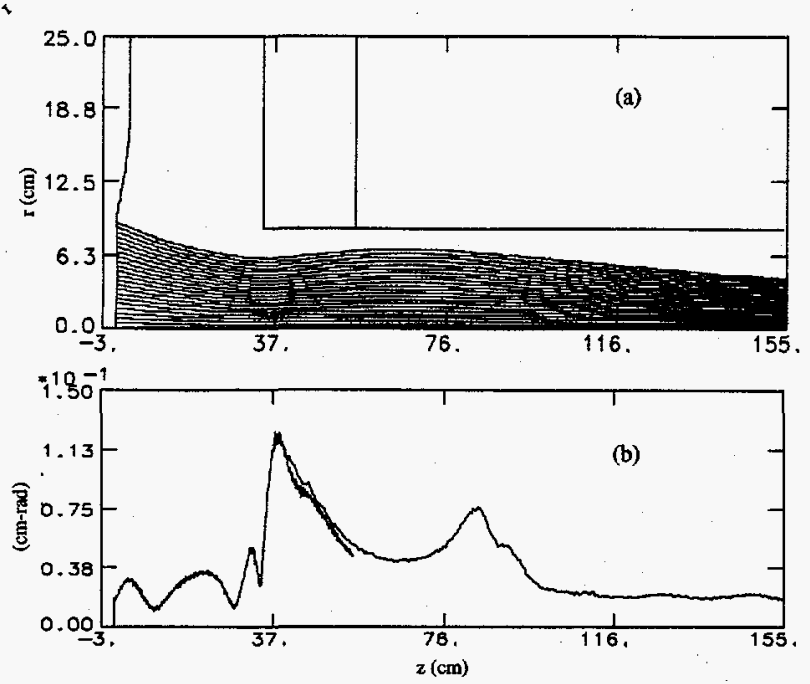

Figure 2: Simulation of $4 \mathrm{MeV}, 4 \mathrm{kA}$ diode in Fig. 2 using IVORY showing (a) particle positions and (b) normalized edge emittance vs. $z$.

of $(1 \mathrm{~mm}, 1 \mathrm{~mm})$ in the AK gap region, transitioning to (4 mm, $2 \mathrm{~mm}$ ) downstream. A cathode temperature of $0.1 \mathrm{eV}$, typical of thermionic emitters, is assumed. The normalized edge emittance as a function of $z$ is shown in Fig. 2(b). The variation of emittance through the AK gap and focusing magnet due to nonlinear self and external fields, has previously been studied [7]. The emittance settles to a reasonably constant value of $0.019 \mathrm{~cm}-\mathrm{rad}$ downstream of the anode magnet. Unlike the ITS beam, this value is dominated by optical effects rather than by the cathode temperature.

To transport the beam further downstream, we use the single-slice code SPROP. This code solves Maxwell's equations on a radial mesh assuming $\partial / \partial z \equiv 0$. It includes the diamagnetic field generated by beam rotation, and the inductive axial self-electric field gives the correct kineticenergy variation of a converging or diverging beam. SPROP is initialized at $z=145.2 \mathrm{~cm}$ with a slice of beam particles from IVORY. To control the beam between the anode magnet and the first cell, we have placed two solenoids between the anode magnet and the first induction-cell magnet. Adjusting these magnets and the first eight cell magnets gives us the beam edge radius and emittance shown in Fig. 3, where we have plotted both the IVORY diode results and the SPROP downstream results. We see that the emittance remains reasonably constant at about $0.019 \mathrm{~cm}$-rad over the $\approx 7$ meter distance.

\section{EFFECT OF ION EMISSION FROM TARGET}

The high space-charge density at the DARHT X-ray converter target gives rise to a large axial electric field (on the order of $4 \mathrm{MeV} / \mathrm{cm}$ ). There is strong experimental evidence $[8,9]$ that anode plasmas are formed when looselybound surface layers (typically hydrocarbons) are heated to

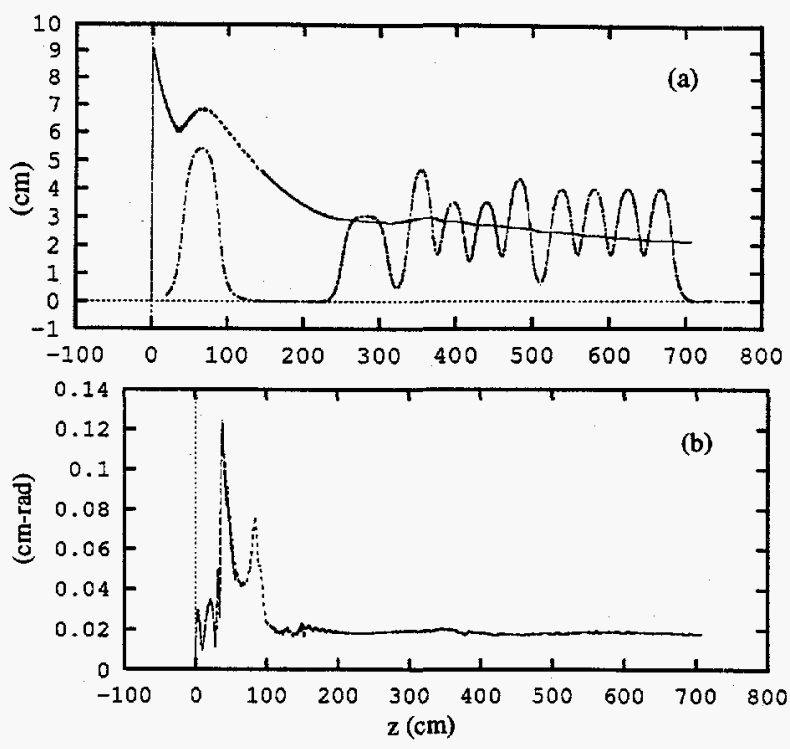

Figure 3: (a) Beam edge radius with overlay of axial magnetic field and (b) normalized emittance from the injector through the first eight cell magnets.

on the order of $400^{\circ} \mathrm{C}$. The layers evaporate off the surface and are ionized by the electron beam, providing a source of positive ions which are accelerated into the beam by the axial electric field. Sanford et al. [8] found evidence of several $A / Z$ (atomic weight/charge state) ratios in the measured ion flux.

To study the effect of ion emission, we carried out simulations with the IPROP code using typical DARHT parameters: $\gamma=40(\approx 20 \mathrm{MeV})$, a current of $4 \mathrm{kA}$, and a normalized edge emittance of $0.1 \mathrm{~cm}$-rad. As shown in Fig. 4, the beam is injected from the open left boundary with a radially inward velocity such that it focuses to a minimum at the conducting right boundary. We assume a space-chargelimited source of a given ion species from regions of the right boundary which are heated to $400^{\circ} \mathrm{C}$.

For the case of protons, the beam radius near the target surface is plotted as a function of time in Fig. 5. The run was stopped soon after ions reached the left boundary. We see that there is a large effect after just a few nanoseconds. The electron and ion positions after $6.7 \mathrm{~ns}$ are shown in Fig. 4. At this time the protons are moving upstream with a velocity on the order of $0.03 c(0.9 \mathrm{~cm} / \mathrm{ns})$. The line chargedensity of the ions is on the order of $10 \%$ of the beam line density, which produces a large radial focusing force on the beam. Initially, the ions cause a decrease in the focal spot, but as they move upstream against the beam, they cause the beam to overfocus.

The calculation was repeated with space-charge-limited emission of singly-ionized tungsten $(A / Z=184)$, giving the $R M S$ radius shown in Fig. 5. The timescale for development of beam pinching increases roughly as the square root of the mass ratio, i.e., a factor $\approx 13$.

The ITS prototype for DARHT $[1,2]$ may allow the ef- 

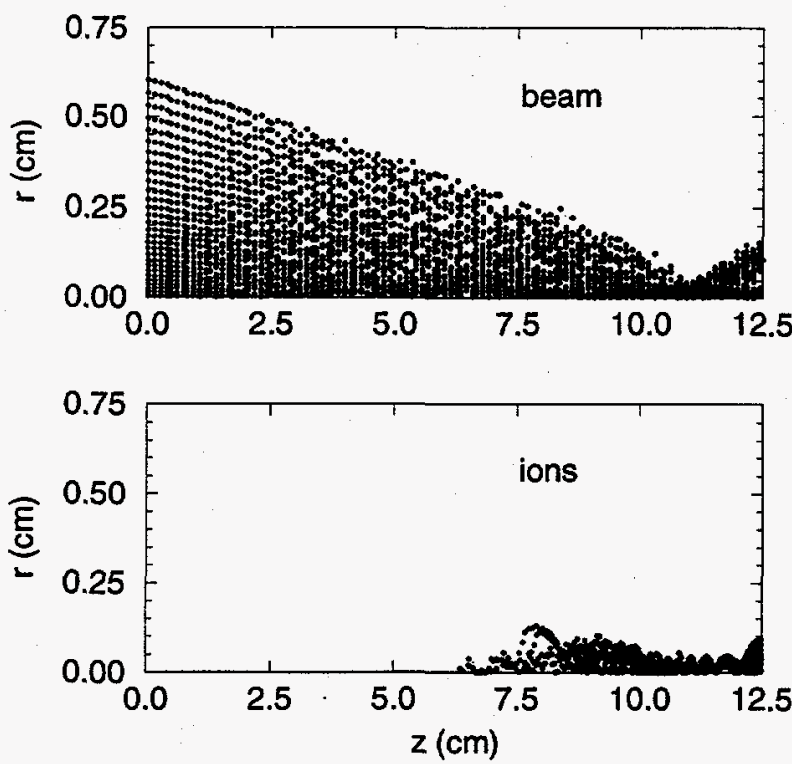

Figure 4: Simulation of space-charge-limited proton emission from target using IPROP. Beam and proton positions are shown after $6.7 \mathrm{~ns}$.

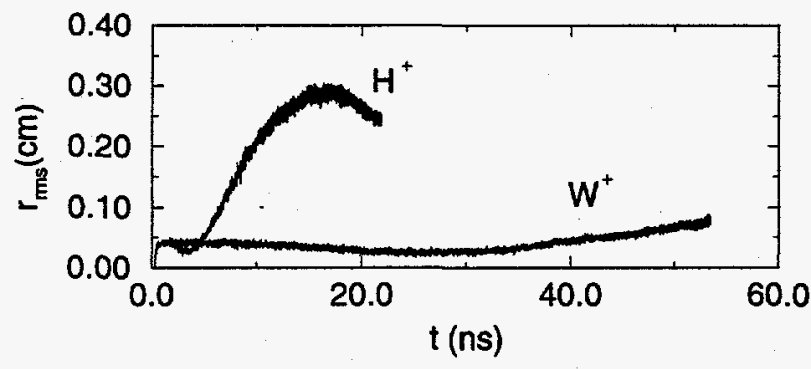

Figure 5: Beam RMS radius near target surface as a function of time for nominal DARHT parameters, with spacecharge-limited emission of $\mathrm{H}^{+}$and $\mathrm{W}^{+}$(singly-ionized tungsten) from target.

fects of target ions to be studied before the DARHT beam is available. The $3.85 \mathrm{kA}, 5.5 \mathrm{MeV}$ beam has a normalized edge emittance of $\approx 0.16 \mathrm{~cm}-\mathrm{rad}$. We have carried out simulations with typical ITS final-focus parameters for two species: $\mathrm{H}^{+}$and $\mathrm{C}^{+}$. The focal spot behavior is shown in Fig. 6. Comparing the $\mathrm{H}^{+}$case with that for DARHT parameters (Fig. 5), we see that because the beam is larger, it takes considerably longer for the ions to have an effect on the beam spot. Nevertheless for both $\mathrm{H}^{+}$and $\mathrm{C}^{+}$there is a large change in the focal spot during a $60 \mathrm{~ns}$ pulse which should be observable with streak-camera diagnostics.

The principal uncertainty in applying these results to experiments is due to the fact that it is difficult to predict the type and abundance of ions produced at the target. Existing streak-camera data [10] from ITS with parameters comparable to those used to obtain Fig. 6 show considerably less variation in radius. Further experiments are currently un-

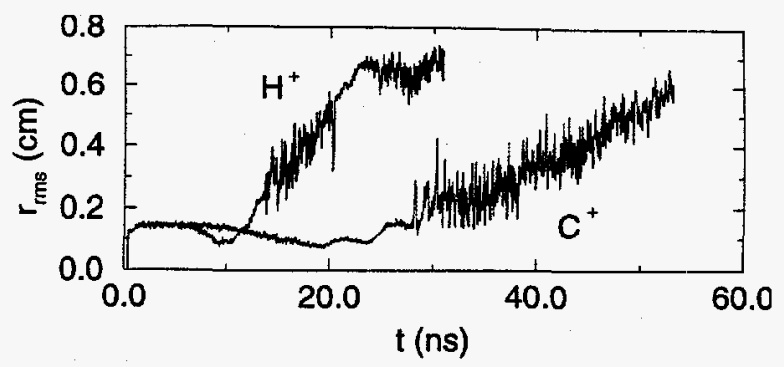

Figure 6: Beam RMS radius near target for ITS parameters with space-charge-limited emission of $\mathrm{H}^{+}$and $\mathrm{C}^{+}$ions from the target.

derway at the ITS and other machines to study the phenomenon in detail $[10,11]$.

Several schemes have been proposed to mitigate the effects of ion emission, including cleaning to remove surface deposits, placing the target in a low-pressure gas cell, and electrically biasing the target. We will await the results of target experiments currently under way before carrying out detailed evaluation of these options.

\section{ACKNOWLEDGMENTS}

This work was carried out under the auspices of the U.S. Department of Energy. We have had useful discussions with Craig Olson (SNL), Dave Moir (LANL), and Dan Prono (LANL) concerning target plasma effects.

\section{REFERENCES}

[1] M. Burns, P. Allison, R. Carlson, J. Downing, D. Moir, and R. Shurter, Proc. XVIII International LINAC Conference, Geneva, 1996. (LA-UR-96-2946).

[2] M. Burns, P. Allison, J. Downing, D. Moir, G. Caporaso, Y. J. Chen, Proc. 9th International Conference on High Power Beams, Washington, May 1992, p. 283.

[3] R. Carlson, J. Downing, J. Melton (LANL) and J. Fockler (PSI), private communication.

[4] T. P. Hughes, D.C. Moir, and P.W. Allison, Proc. 1995 Particle Accelerator Conference, p. 1207.

[5] J. Fockler et al., Proc. 8th International Pulsed Power Conference, San Diego, 1996, p. 177.

[6] J.E. Boers, Proc. 1995 Particle Accelerator Conference, p. 2312.

[7] T.P. Hughes, R. L. Carlson, and D.C. Moir, J. Appl. Phys. 68, 2562 (1990).

[8] T. W. L. Sanford, J. A. Halbleib, J. W. Poukey, A. L. Pregenzer, R.C. Pate, C. E. Heath, R. Mock, G. A. Mastin, and D. C. Ghiglia, J. Appl. Phys. 66, 10 (1989).

[9] D. R. Welch, M. E. Cuneo, C.L. Olson, and T. A. Melhorn, Phys. Plasmas 3, 2113 (1996).

[10] D. Moir (LANL), private communication.

[11] D. Prono (LANL), private communication. 